\title{
New Knowledge About Old Drugs: The Anti-Inflammatory Properties of Cardiac Glycosides*
}

Authors

Robert Fürst, Ilse Zündorf, Theo Dingermann

\author{
Affiliation \\ Institute of Pharmaceutical Biology, Biocenter, \\ Goethe University, Frankfurt/Main
}

Key words

cardiac glycosides, ouabain, inflammation, animal models, molecular mechanisms

$\begin{array}{ll}\text { received } & \text { January 27, } 2017 \\ \text { revised } & \text { February 20, } 2017 \\ \text { accepted } & \text { March 2, 2017 }\end{array}$

Bibliography

DOI http://dx.doi.org/10.1055/s-0043-105390

Published online March 15, 2017 | Planta Med 2017; 83: 977-

984 ㄷ Georg Thieme Verlag KG Stuttgart · New York I

ISSN 0032-0943

Correspondence

Robert Fürst, PhD

Institute of Pharmaceutical Biology, Biocenter,

Goethe University

Max-von-Laue-Str. 9, 60438 Frankfurt/Main

Phone: + 496979829655 , Fax: + 496979876329655

fuerst@em.uni-frankfurt.de

\begin{abstract}
In the 19th century, cardio-active steroid glycosides, shortly cardiac glycosides, were scientifically established as drugs against heart failure. Their in vivo, cellular, and molecular actions as well as their predominant target, $\mathrm{Na}^{+}-\mathrm{K}^{+}$-ATPase, have been comprehensively investigated in the 20th century and the discovery of endogenous cardiac glycosides has fostered this research field. In the last years, however, results from clinical trials and meta-analyses have questioned their therapeutic value due to efficacy and safety issues. This has led to a considerable decline of their usage. Beyond the cardiovascular system, cardiac glycosides have been increasingly recognized as antitumor compounds and $\mathrm{Na}^{+}-\mathrm{K}^{+}$-ATPase has evolved into a promising drug target in oncology. A wealth of review articles exists that intensively discuss these topics. Surprisingly, the anti-inflammatory actions of cardiac glycosides, which were discovered in the 1960 s, have so far hardly been perceived and have not yet been summarized. This review provides an overview of the in vivo and in vitro actions of cardiac glycosides on inflammatory processes and of the signaling mechanisms responsible for these effects: cardiac glycosides have been found to decrease inflammatory symptoms in different animal models of acute and chronic inflammation. Regarding the underlying mechanisms most research has focused on leukocytes. In these cells, cardiac glycosides primarily inhibit cell proliferation and the secretion of proinflammatory cytokines.
\end{abstract}

\section{Cardio-Active Steroid Glycosides Against Heart Failure: Ups and Downs}

Plants that contain cardio-active steroid glycosides (CGs) have been therapeutically used since ancient times. For instance, the usage of squill, Drimia maritima (L.) Stearn (Asparagaceae), was reported in the Ebers Papyrus [1]. At the beginning of the early modern history, the German botanist Leonhard Fuchs, who created the scientific name Digitalis for foxglove, described the plant in detail and recommended it for diuresis. However, due to the very difficult dosage, which is based on the narrow therapeutic index of CGs [2], digitalis therapy did not succeed at that time.

The successful usage of foxglove, Digitalis purpurea L. (Plantaginaceae; $>$ Fig. 1), started in 1785 with a publication by the English

* Part of the special issue dedicated to Professor Max Wichtl. physician William Withering. Due to his investigations, he could make clear recommendations on the preparation and dosage of the herbal remedy against dropsy (heart failure-associated edema) [1]. Unfortunately, the digitalis therapy became too successful: It was carelessly propagated as a universal remedy, which led to severe reservations among physicians and, consequently, to a shift away from this herbal remedy [3].

The next revival of digitalis started in the middle of the 19th century and was based on the experimental and clinical research by Ludwig Traube in Berlin and on the isolation of CGs by Oswald Schmiedeberg in Strasbourg [1]. With the beginning of the 20th century, digitalis therapy became the gold standard for the treatment of heart failure. A further research milestone was achieved in 1965 when the German pharmacologist Kurt Repke identified the cell membrane-located ion pump $\mathrm{Na}^{+}-\mathrm{K}^{+}$-ATPase as the molecular target of CGs [4]. Besides their action on this pump, they were also found to exert sympathoinhibitory effects and to increase the vagal tone [5]. 


\begin{tabular}{ll}
\hline ABBREVIATIONS \\
CFTR & cystic fibrosis conductance regulator \\
CG & cardio-active steroid glycoside \\
DC & dendritic cell \\
IL & interleukin \\
iNOS & inducible nitric oxide synthase \\
IKB & inhibitor of $\kappa$ B \\
LPS & lipopolysaccharide \\
MAPK & mitogen-activated protein kinase \\
Na+-K+-ATPase & sodium potassium adenosine tri- \\
& phosphatase \\
NF $\kappa B$ & nuclear factor $\kappa$ B \\
PBMC & peripheral blood mononuclear cells \\
ROR $\gamma t$ & retinoid acid receptor-related orphan \\
& nuclear receptor $\gamma$ t \\
TNF $\alpha$ & tumor necrosis factor $\alpha$ \\
VCAM-1 & vascular cell adhesion molecule 1 \\
&
\end{tabular}

The discovery of the binding of CGs to the $\mathrm{Na}^{+}-\mathrm{K}^{+}$-ATPase nourished speculations that endogenous CGs, so-called digitalis- or ouabain-like factors, might exist that serve as ligands of this target. In the late 1980s, hints to the existence of endogenous CGs intensified [6-8] and in the early 1990s, these compounds were eventually discovered [9-13]. Their biosynthesis, tissue of origin, and precise physiological as well as pathophysiological function is an ongoing matter of research and debate [14]. Interestingly, in critically ill patients (not treated with CGs) Berendes et al. [15] found that the occurrence of endogenous CGs in the blood was associated with an increased risk of mortality. The authors speculated that the secretion of endogenous CGs depends not only on the impaired myocardial function and the volume overload in these patients, but also on systemic inflammation. However, it is an open question whether the endogenous CGs are a mechanism of protection or part of the detrimental pathology.

Surprisingly, despite their intensive clinical use, randomized controlled trials with CGs have not been performed until the end of the 20th century. The results of these trials and of the respective meta-analyses were sobering: Both the efficacy and the safety of the digitalis-based therapy of heart failure were questioned [16-22]. Since well-tolerated alternative drugs, such as angiotensin-converting enzyme inhibitors and $\beta$-blockers, that show clear benefits on the mortality of heart failure patients are available, the use of cardiac glycosides has declined increasingly.

\section{Cardio-Active Steroid Glycosides as Antitumor Agents: A Well Evolved Field}

CGs currently experience a fascinating renaissance in a completely different field: They are evaluated as cancer-preventive as well as anticancer drugs ( $\triangleright$ Fig. 2). Their antitumor action was discovered 50 years ago: In 1967, Osamu Shiratori [23] from the Japanese company Shionogi reported about the antiproliferative action of several CGs isolated from Digitalis purpurea on neoplastic cells in vitro and in vivo. Moreover, an epidemiologic study published in 1979 indicated that women who were treated with CGs and who developed breast cancer showed a less aggressive tumor growth and lower metastases formation [24]. These discoveries triggered huge research efforts and, most importantly, fueled the idea of the $\mathrm{Na}^{+}-\mathrm{K}^{+}$-ATPase as a promising drug target for the treatment of different types of cancer. The mechanistic basis of these actions has been intensively studied in the last years: CGs inhibit cancer cell growth by various complex and cell-type dependent mechanisms, e.g. by inducing apoptosis or autophagy, by triggering mitochondrial dysfunction due to an accumulation of calcium, and/or by interfering with the mammalian target of rapamycin (mTOR) and NFKB signaling. Recent comprehensive reviews that summarize this vibrant field of research can be found under the references [25-30].

\section{A New Frontier: The Anti-Inflammatory Potential of Cardio-Active Steroid Glycosides}

A schematic overview of the subsequently described actions of CGs is provided in > Fig. 2.

\section{Cardio-active steroid glycosides exert anti-inflammatory actions in vivo}

\section{Acute inflammation}

The first report on the influence of CGs on inflammatory processes was published in 1967: Lancaster and Vegad [31] found that pretreatment with ouabain (also known as g-strophanthin) $(100 \mathrm{\mu g} / \mathrm{kg}$ bodyweight; $~ F i g .3)$ reduced the turpentine-triggered early signs of inflammation (edema formation) in the skin and pleural cavity of sheep. De Vasconcelos et al. [32] tested the action of ouabain in different murine models of inflammation and algesia: The authors reported that ouabain $(310$ or $560 \mu \mathrm{g} / \mathrm{kg}$ bodyweight) decreased paw edema formation in mice induced by carrageenan, compound 48/80, zymosan, prostaglandine E2, and bradykinine. Also the concanavalin A-evoked peritoneal inflammation and the associated presence of leukocytes in the peritoneal cavity was reduced by the CG. Moreover, ouabain exhibited nociceptive actions in the acetic acid-induced writhing response and in the hot plate model. These findings were corroborated and expanded in a study by Leite et al. [33], who showed that ouabain $(560 \mu \mathrm{g} / \mathrm{kg}$ bodyweight) decreased zymosan-induced peritonitis in mice. The compound reduced fluid extravasation (edema formation), leukocyte infiltration and the levels of the cytokines IL-1 $\beta$ and tumor necrosis factor $\alpha$ (TNF $\alpha$ ), but did not influence the viability or function (phagocytosis) of leukocytes. The reduced leukocyte extravasation was attributed to a reduced migratory capacity evoked by ouabain. Moreover, ouabain was found to inhibit the zymosan-induced DNA-binding activity of the prototypical proinflammatory transcription factor NF $K$ B. Taken together, these studies provide clear evidence that ouabain effectively prevents acute inflammation in vivo. 


\section{Infection-induced inflammation}

The activation of inflammatory processes is a prerequisite for the successful elimination of pathogens. Anthony Esposito [34] published his findings on the action of digoxin $(4 \mu \mathrm{g} / \mathrm{kg}$ bodyweight per day; • Fig. 4) on the inflammatory response in murine pneumococcal pneumonia. The digoxin-treated animals exhibited a higher mortality rate, since they were unable to clear the infection. Interestingly, these mice showed a decreased recruitment of granulocytes and macrophages into the lung tissue, whereas, at least in vitro, digoxin did not affect the bacteria-killing action of alveolar macrophages. Jacob et al. [35] investigated the action of ouabain in murine leishmaniosis. The CG effectively prevented the infiltration of the peritoneal cavity with neutrophils and reduced the levels of TNF $\alpha$ and interferon $\gamma$ (IFNY) in the peritoneal exudate.

\section{Chronic inflammatory autoimmune diseases}

Regarding autoimmune diseases, digoxin was first evaluated in an animal model resembling multiple sclerosis: Huh and coworkers [36] were seeking for small molecule inhibitors of the retinoid acid receptor-related orphan nuclear receptor RORyt, a transcription factor required for the differentiation of $T_{H} 17$ cells. In the last years, these cells have been recognized to play a crucial role in autoimmune diseases. In a compound screening approach digoxin was discovered as specific inhibitor of RORyt. In fact, digoxin was found to inhibit murine $T_{H} 17$ cell differentiation. In murine experimental autoimmune encephalomyelitis, a model of multiple sclerosis, digoxin ( $40 \mu \mathrm{g}$ per mouse) delayed the onset and reduced the severity of the disease. Moreover, it strongly decreased the infiltration of the spinal cord with $T_{H} 17$ cells. To overcome the limitations of CGs regarding their toxicity, the authors searched for chemical modifications of digoxin with a decreased affinity to the $\mathrm{Na}^{+}-\mathrm{K}^{+}$-ATPase and an augmented affinity to RORyt and identified the two compounds 20,22-dihydrodigoxin-21,23-diol and digoxin-21-salicylidene. Inspired by these important findings on the influence of $C G$ s on $T_{H} 17$ cells, the action of digoxin was tested in two further models of autoimmune diseases: Lee et al. [37] provided evidence for both a preventive and therapeutic action of digoxin ( 2 and $5 \mathrm{mg} / \mathrm{kg}$ bodyweight) on collagen-induced arthritis in mice. Digoxin lowered the joint inflammation and reduced the expression of IL-17, IL-1 $\beta$, IL-6, TNF $\alpha$, and IL-21. The digoxin-treated mice showed a decreased amount of $\mathrm{T}_{H} 17$ cells and an increased number of regulatory $T$ cells. In vitro, digoxin suppressed the differentiation of $T_{H} 17$ cells and reduced the production of immunoglobulins from murine B cells. Furthermore, digoxin was tested in experimental autoimmune uveitis in mice. Hinshaw et al. [38] found that digoxin ( $2 \mathrm{mg} / \mathrm{kg}$ bodyweight) reduced uveal inflammation and inhibited the differentiation of $T_{H} 17$ cells. Unfortunately, this anti-inflammatory action was accompanied by a severe retinal degeneration process that led to the loss of vision. Obviously, digoxin is an improper compound to treat uveitis. These findings strengthen the approach of Huh et al. [36] to separate the actions on RORyt from those on the $\mathrm{Na}^{+}-\mathrm{K}^{+}$-ATPase.

\section{Neuroinflammation}

Forshammar et al. [39] reported about the beneficial action of CGs on LPS-activated astrocytes. Both a very low (1 pM) and a very

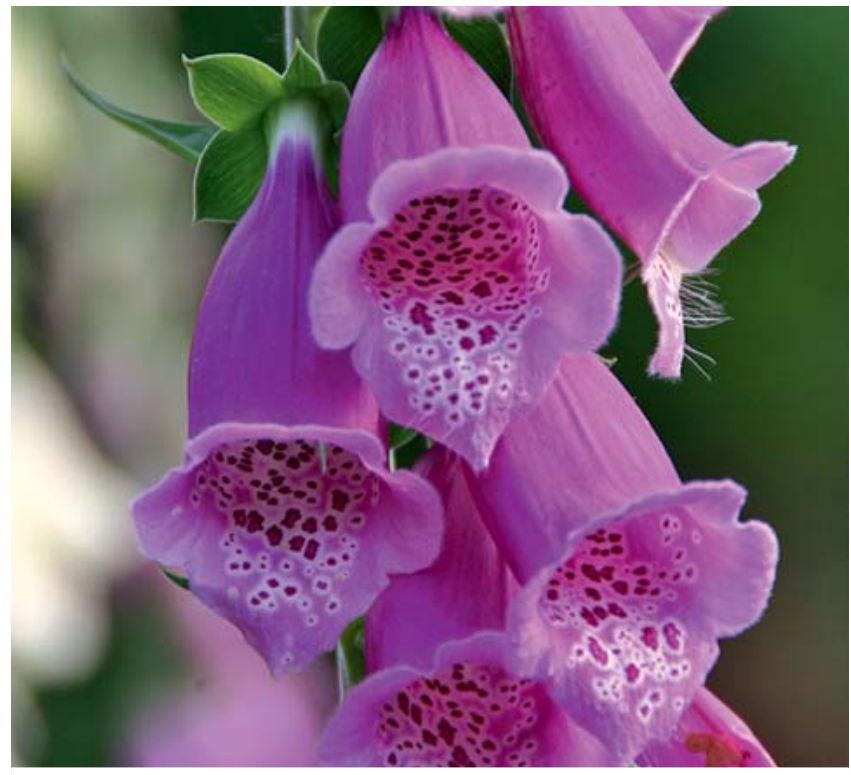

- Fig. 1 Digitalis purpurea L. (Plantaginaceae), photographed by Dr. Ilse Zündorf.

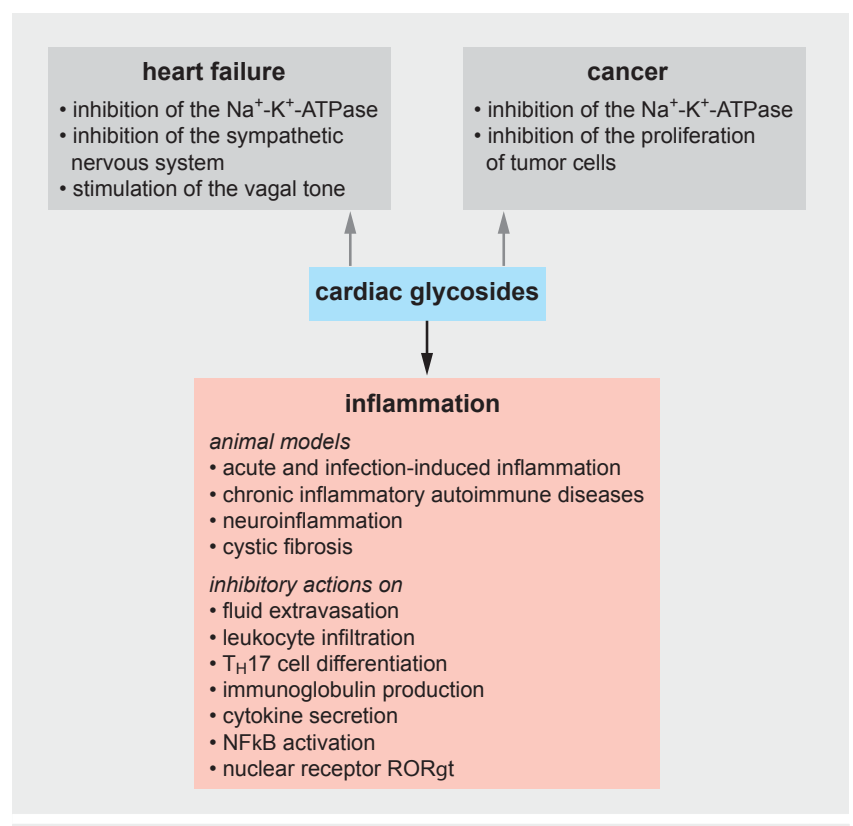

- Fig. 2 Major effects of cardiac glycosides.

high concentration $(10 \mu \mathrm{M})$ of ouabain prevented the downregulation of the $\mathrm{Na}^{+}-\mathrm{K}^{+}$-ATPase, restored the disorganized F-actin cytoskeleton, and reduced the secretion of IL-1 $\beta$. Forshammar and colleagues [40] also investigated the action of ouabain on rat microglia cells which represent resident brain macrophages. Interestingly, in contrast to astrocytes ouabain did not exert any influence on the LPS-induced secretion of cytokines from microglia. In vivo experiments in the context of neuroinflammation were performed by Kinoshita et al. [41] who evaluated the effect of oua- 


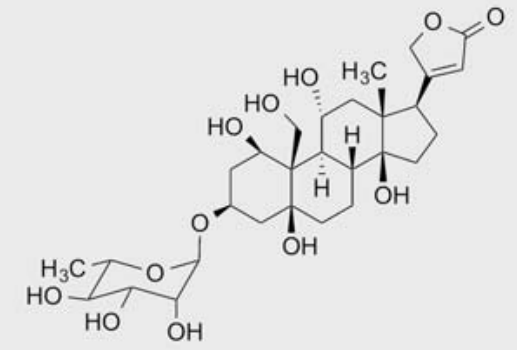

- Fig. 3 Chemical structure of ouabain (g-strophanthin).

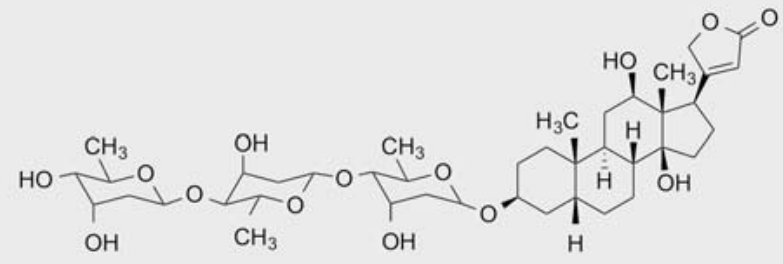

- Fig. 4 Chemical structure of digoxin.

bain $(1.8 \mu \mathrm{g} / \mathrm{kg}$ bodyweight) on the hippocampus in a rat model of LPS-induced systemic inflammation/sepsis. Ouabain reduced the LPS-triggered activation of astrocytes, inhibited the raise of the proapoptotic protein Bax, and maintained the expression of the brain-derived neurotrophic factor which indicates a neuroprotective action. Furthermore, ouabain decreased the nuclear translocation of $\mathrm{NF} \kappa \mathrm{B}$ p65 and the degradation of $I_{\kappa} \mathrm{B}$ as well as the expression of IL-1 $\beta$ and of iNOS. Surprisingly, the elevated serum levels of corticosterone and TNF $\alpha$ were not altered by ouabain. Although neither LPS nor ouabain affected the activity of the hippocampal $\mathrm{Na}^{+}-\mathrm{K}^{+}$-ATPase, an alternative target which might be responsible for the observed pharmacological actions of ouabain was not presented.

\section{Cystic fibrosis}

Cystic fibrosis is a genetic disease caused by the lack or a malfunction of the chloride channel cystic fibrosis conductance regulator (CFTR). It is characterized by severe lung inflammation and high levels of the proinflammatory cytokine IL-8 in lung tissues. In 2004, Srivastava et al. [42] reported that different CGs (e.g. digitoxin, ouabain, oleandrin) suppress IL-8 hypersecretion in vitro in cystic fibrosis lung epithelial cells. With an $\mathrm{IC}_{50}$ of $0.9 \mathrm{nM}$, digitoxin was the most active CG. Moreover, the authors tested the influence of digitoxin on the global gene expression in these cells and compared the gene expression patterns with those obtained upon restoral of the lacking CFTR ion channel. Interestingly, digitoxin could mimic the effect of this genetic restoral and the overlapping regulated genes were associated with the TNF $\alpha / N F \kappa B$ pathway. This work was followed-up one year later: In a detailed mechanis- tic analysis, CGs were found to block the TNF $\alpha$-dependent recruitment of the adaptor protein TNF receptor-associated death domain (TRADD) to the TNF receptor 1 (TNFR1) [43]. This explains the observed inhibitory action of digitoxin on the activation of IKK and on the phosphorylation and degradation of $\mathrm{IKB}_{\mathrm{K}} \mathrm{.}$

Inspired by these two in vitro studies, Zeitlin et al. [44] initiated an explorative randomized controlled trial: 24 patients suffering from mild to moderate cystic fibrosis were treated over a period of 28 days with digitoxin ( $50 \mu \mathrm{g}$ or $100 \mu \mathrm{g}$ daily) or with placebo. As primary parameters, the concentration of IL-8 and the count of neutrophils in the sputum were analyzed. The therapy was safe, but steady state blood concentrations of digitoxin could not be achieved until the last few days of the treatment period. Since the duration of the trail was too short, there was no chance to reveal statistically significant outcomes. In fact, digitoxin did not alter IL-8 levels and only slightly reduced the neutrophil count. Larger and much longer studies are needed to answer the question as to whether CGs can beneficially influence inflammatory processes in cystic fibrosis patients.

\section{Ouabain exerts immunomodulatory actions on leukocytes}

A schematic overview of the subsequently described effects of CGs on the different types of leukocytes is provided in $>$ Fig. $\mathbf{5}$.

\section{Lymphocytes}

In 1968, Quastel and Kaplan [45] reported that ouabain ( $\geq 10 \mathrm{nM}$ ) blocks DNA synthesis induced by the mitogen phytohaemagglutinin in isolated human lymphocytes. As expected due to the inhibition of the $\mathrm{Na}^{+}-\mathrm{K}^{+}$-ATPase, the effect could be reversed by increasing potassium concentrations in the culture medium. In a followup article [46], the authors corroborated and expanded these findings: ouabain ( $\geq 10 \mathrm{nM}$ ) did not only inhibit the mitogen-triggered DNA, but also the RNA and protein synthesis in lymphocytes. Of note, the inhibitory action of ouabain $(1-10 \mu \mathrm{M})$ on the de novo protein synthesis was confirmed in a recent work by Takada et al. [47], who additionally showed that ouabain decreases the $\mathrm{Na}^{+}$-dependent amino acid transport across cell membranes. However, the authors used a human lung carcinoma cell line in this study. After these initial reports, the field was not advanced for a decade. Then, in 1980, Szamel et al. [48] published an article in which they refined the findings of Quastel and Kaplan on the inhibition of ouabain on lymphocytes $[45,46]$. They analyzed the action of ouabain $(20 \mathrm{nM})$ in dependence of the cell cycle status and showed that lymphocytes were most sensitive to ouabain within the $S$ phase. In a further article, Szamel et al. [49] reported that ouabain $(5 \mu \mathrm{M})$ is also able to block a very early event in the activation of lymphocytes, i.e. the altered metabolism of plasma membrane phospholipids (e.g. oleate incorporation), by inhibiting the acyl-CoA lysolecithin-acyltransferase due to a functional and spatial association of this enzyme with $\mathrm{Na}^{+}$$\mathrm{K}^{+}$-ATPase. Furthermore, ouabain $(100 \mathrm{nM})$ reduced both the phytohaemagglutinin- and the phorbol ester-induced proliferation of peripheral blood lymphocytes [50]. Despite this inhibition of proliferation, the lymphocytes could still be activated.

As a consequence of the discovery of IL-2 as an important regulator of T cells in the late 1970s, Stoeck et al. [51] wondered 


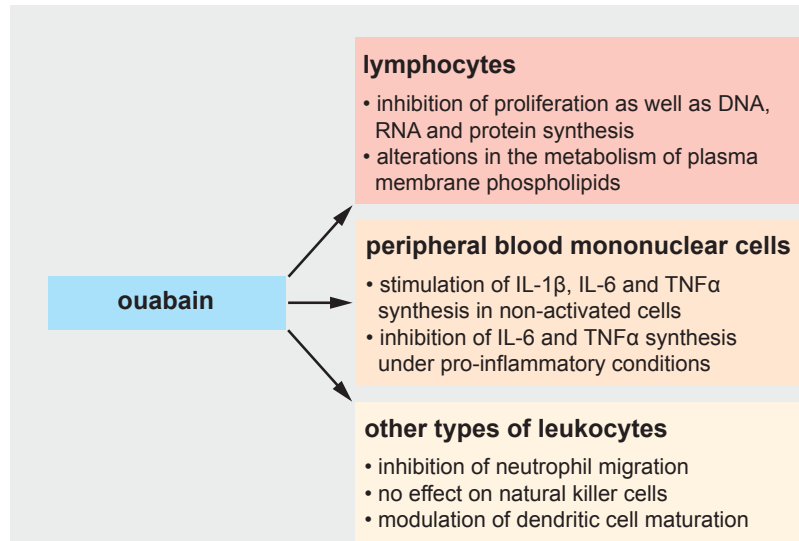

- Fig. 5 Summary of the effects of ouabain on leukocytes.

whether the actions of ouabain on T lymphocytes could depend on alterations in the production of IL-2 and/or the response to this cytokine. Indeed, ouabain $(100 \mu \mathrm{M})$ clearly decreased the mitogenic activity of IL-2 on T cells, but only moderately reduced the concanavalin A-triggered IL-2 production. These findings were confirmed by Lillehoj and Shevach [52] and studied in great detail by Dornand et al. [53]. Of note, ouabain, up to a concentration of $10 \mathrm{mM}$ and a treatment period of $30 \mathrm{~h}$, did not alter the viability of isolated human lymphocytes despite inhibition of the $\mathrm{Na}^{+}-\mathrm{K}^{+}$ATPase [54].

In thymocytes, which represent hematopoietic progenitor cells in the thymus, a high concentration of ouabain $(5 \mu \mathrm{M})$ inhibited the mitogen-induced proliferation [55]. Also a much lower concentration $(100 \mathrm{nM})$ was able to decrease thymocyte activation via reducing the phosphorylation of MAPK p38 and the levels of the nuclear factor of activated T cells (NFAT) c1 [56]. In contrast, ouabain (100 nM) was reported to augment intracellular calcium concentrations and to enhance the expression of CD69, an indicator of thymocyte activation [57]. Moreover, ouabain and glucocorticoids synergistically increased the death of thymocytes [58, 59]. The pathophysiological meaning of these results, however, remains elusive.

Besides T lymphocytes, also B cells were found to be susceptible to ouabain: Milthorp et al. [60] demonstrated that ouabain $(10 \mu \mathrm{M})$ inhibits the production of antibodies in splenocytes from pigs and rabbits, but not from mice.

\section{Peripheral blood mononuclear cells}

In the late 1990s, the influence of CGs on the cytokine secretion from PBMCs (monocytes and lymphocytes) was investigated in detail. These studies provided an interesting and very important insight into the differential actions of CGs: the influence of ouabain on the cytokine production of PBMCs strongly depends on their activation status. Based on the finding that the activity of the $\mathrm{Na}^{+}-\mathrm{K}^{+}$-ATPase is decreased in PBMCs from rheumatoid arthritis patients [61], Foey et al. [62] showed that mimicking this pathological situation in isolated human PBMCs from healthy donors by treating these cells with ouabain $(100 \mathrm{nM})$ strongly augments IL-1 $\beta$ and TNF $\alpha$, but suppresses IL- 6 secretion. Thus, an impaired function of the $\mathrm{Na}^{+}-\mathrm{K}^{+}$-ATPase might be associated with the increased levels of proinflammatory cytokines in patients with rheumatoid arthritis. Matsumori et al. [63] also obtained PBMCs from healthy human donors. In their setting, the expression (mRNA and protein) of all three proinflammatory cytokines, IL-1 $\beta, \mathrm{TNF} \alpha$, and IL-6, was increased by ouabain $(100 \mathrm{nM})$. After activation of PBMCs with LPS, however, ouabain suppressed the production of IL- 6 and TNF $\alpha$. This was in line with the in vivo results: ouabain $(1 \mathrm{mg} / \mathrm{kg}$ bodyweight) protected mice from the LPS-induced lethal toxicity and reduced the levels of IL-6 and TNF $\alpha$. In a followup study, Matsumori et al. [64] could show that the calcium channel blocker amlodipine blocked the ouabain $(1 \mu \mathrm{M})$-triggered increase of IL- $1 \alpha$, IL- $1 \beta$, and IL- 6 in PBMCs from healthy human donors.

In 2008, Ihenetu et al. [65] confirmed the earlier reports on the action of CGs on human PBMCs: Both digoxin (<100 nM) and the endogenous digoxin-like immunoreactive factors (DLIF) inhibited the LPS-triggered activation of NFKB and the release of TNF $\alpha$, IL-6, and IL-8.

\section{Monocytes and macrophages}

Sowa and Przewlocki [66] analyzed the release of nitric oxide (NO), an important defense mechanism of the innate immunity, from rat peritoneal macrophages. They found that ouabain $(125-500 \mu \mathrm{M})$ does not affect basal NO generation, however, it strongly enhanced the LPS-induced NO formation. In monocytes purified from human PBMCs (healthy donors), ouabain treatment $(100 \mathrm{nM})$ resulted in a decreased expression of the membranebound form of CD14 [67]. This effect was based on the activation of the epidermal growth factor receptor and p38 MAPK. Furthermore, ouabain (10 nM) augmented the intracellular calcium concentration, the surface levels of the activation markers CD69, HLA-DR, CD86 and CD80, the expression of IL- $1 \beta$ and TNF $\alpha$, and the endocytic activity of these cells [68].

\section{Neutrophils, natural killer cells and dendritic cells}

Ward and Becker [69] found that ouabain inhibits the chemotactic migration of rabbit neutrophils, but the $\mathrm{IC}_{50}$ value was quite high, ranging between 1-100 $\mu \mathrm{M}$. De Moraes et al. [70] wondered whether natural killer cells are also prone to the action of ouabain. However, they could clearly demonstrate that ouabain does not influence these cells. Nascimento et al. [71] were the first to investigate the action of ouabain (100 nM) on human dendritic cells (DCs). Interestingly, the TNF-induced expression of CD83 and the production of IL-12, two features of DC maturation, were reduced by ouabain, whereas the capability of DCs to activate lymphocytes remained unaltered.

\section{Cardiac Glycosides Decrease the Inflammatory Activation of Endothelial Cells}

Endothelial cells are not only a crucial part of the vascular system, but also regulate inflammatory processes, such as the extravasation of immune cells from the blood into the tissue. Up to now, only two studies have dealt with the actions of CGs on endothelial cells in the context of inflammation. Bereta et al. [72] showed that 
ouabain activates NFKB and increases the expression of the NFKB target genes iNOS and VCAM-1 in murine brain endothelial cells. Furthermore, digitoxin was found to strongly inhibit the IL- $1 \beta$-induced expression of an important proinflammatory mediator, the monocyte chemoattractant protein-1 (MCP-1), and of VCAM-1 [73]. Most importantly, this study also showed that digitoxin inhibits the adhesion of monocytes to endothelial cells. Regarding the underlying mechanisms, digitoxin blocked the NFKB cascade as well as the activation of the extracellular signal-regulated kinase (ERK), but not of p38 MAPK and c-Jun N-terminal kinase (JNK). Moreover, digitoxin augmented the activity of the endothelial NO synthase (eNOS) and prevented the TNF $\alpha$-caused apoptosis of endothelial cells via activation of the phosphatidyl-inositol3-kinase (PI3K)/Akt pathway.

\section{Summary and Conclusion}

The first report on the anti-inflammatory potential of CGs dates back 50 years. Since then, CGs have been tested in several animal models of inflammation ranging from acute and infection-triggered models to chronic inflammatory disease. Despite this knowledge, a translation into clinical applications has not yet occurred. This might be due to the following unresolved issues that call for further research:

CGs have been found to exert anti-inflammatory actions not only by targeting the $\mathrm{Na}^{+}-\mathrm{K}^{+}$-ATPase, but also via different systems, such as RORyt. Thus, the role of the ATPase for the anti-inflammatory action of CGs is still unclear. This issue is of high relevance, since the toxic activities of CGs are mainly ascribed to this enzyme. The separation of the cardiovascular $/ \mathrm{Na}^{+}-\mathrm{K}^{+}$-ATPase-inhibiting effects from the anti-inflammatory activities has been shown to be feasible. Further approaches into this direction are, thus, of great importance and will strongly advance the field.

Most of the studies analyzed the actions of CGs on leukocytes. A major drawback of these analyses is the fact that highly different concentrations of CGs which do not properly reflect the in vivo situation were used. Physiological levels of endogenous CGs range from $10 \mathrm{pM}$ to $1 \mathrm{nM}$. In contrast, both the plasma concentrations of endogenous CGs during stress conditions and the serum levels of administered CGs during pharmacotherapy are much higher, namely in the range of $100 \mathrm{nM}[74,75]$. Also species differences have not yet been considered systematically. Thus, from the clinical perspective, some of the reported effects and presented mechanisms might only be of limited relevance.

Up to now, only one very small and preliminary clinical trial has investigated the anti-inflammatory potential of CGs (in the context of cystic fibrosis). Unfortunately, due to the very limited period of drug treatment, the study could not demonstrate significant benefits of CGs. However, the effort to perform clinical trials is highly appreciated and needs to be expanded urgently.

Interestingly, although the pathogenesis of many types of tumors is closely associated with inflammatory processes, no data about the action of CGs on the interface between cancer and inflammation exist. As a future direction, it would be of great interest to investigate both the pathophysiological role of endogenous
CGs and the pharmacological action of exogenously applied CGs in the context of inflammation-associated tumorigenesis.

Taken together, CGs possess a very interesting anti-inflammatory potential. However, the usage of unmodified CGs seems to be very unlikely due to their narrow therapeutic index. The rational design of CG analogs with decreased cardiac and augmented anti-inflammatory actions is a young but promising research area that will greatly advance the field.

\section{Conflict of Interest}

The authors declare no conflict of interest.

\section{References}

[1] Greeff K, Schadewaldt H. Introduction and Remarks on the History of cardiac Glycosides. In: Greeff K, ed. Cardiac Glycosides. Berlin, Heidelberg: Springer; 1981: 1-12

[2] Lampe D, Lampe H, Berwing K, Parsi RA, Mai I. On the problem of optimum digitlaization in man. Int J Clin Pharmacol Biopharm 1978; 16: 380-383

[3] Regal W, Nanut M. Von der Geheimrezeptur zum Herzglykosid. Available at http://www.springermedizin.at/artikel/2184-von-dergeheimrezeptur-zum-herzglykosid. Accessed January 5, 2017

[4] Repke K, Portius H]. Comparison of the effect of steroid lactones on the transport-ATPase and ion transport of erythrocytes. Folia Haematol Int Mag Klin Morphol Blutforsch 1965; 83: 108-118

[5] Ferguson DW, Berg WJ, Sanders JS, Roach PJ, Kempf JS, Kienzle MG. Sympathoinhibitory responses to digitalis glycosides in heart failure patients. Direct evidence from sympathetic neural recordings. Circulation 1989; 80: 65-77

[6] Haddy F]. Endogenous digitalis-like factor or factors. N Engl J Med 1987; 316: 621-623

[7] Poston L. Endogenous sodium pump inhibitors: a role in essential hypertension? Clin Sci (Lond) 1987; 72: 647-655

[8] Haber E, Haupert GT jr. The search for a hypothalamic $\mathrm{Na}^{+}, \mathrm{K}^{+}$-ATPase inhibitor. Hypertension 1987; 9: 315-324

[9] Goto A, Yamada K, Ishii M, Yoshioka M, Ishiguro T, Eguchi C, Sugimoto T. Purification and characterization of human urine-derived digitalis-like factor. Biochem Biophys Res Commun 1988; 154: 847-853

[10] Goto A, Ishiguro T, Yamada K, Ishii M, Yoshioka M, Eguchi C, Shimora M, Sugimoto T. Isolation of a urinary digitalis-like factor indistinguishable from digoxin. Biochem Biophys Res Commun 1990; 173: 1093-1101

[11] Hamlyn JM, Blaustein MP, Bova S, DuCharme DW, Harris DW, Mandel F, Mathews WR, Ludens JH. Identification and characterization of a ouabain-like compound from human plasma. Proc Natl Acad Sci U S A 1991; 88: 6259-6263

[12] Bova S, Blaustein MP, Ludens JH, Harris DW, DuCharme DW, Hamlyn JM. Effects of an endogenous ouabainlike compound on heart and aorta. Hypertension 1991; 17: 944-950

[13] Ferrandi M, Manunta P, Balzan S, Hamlyn JM, Bianchi G, Ferrari P. Ouabain-like factor quantification in mammalian tissues and plasma: comparison of two independent assays. Hypertension 1997; 30: 886-896

[14] Buckalew VM. Endogenous digitalis-like factors: an overview of the history. Front Endocrinol (Lausanne) 2015; 6: 49

[15] Berendes E, Cullen P, Van Aken H, Zidek W, Erren M, Hübschen M, Weber T, Wirtz S, Tepel M, Walter M. Endogenous glycosides in critically ill patients. Crit Care Med 2003; 31: 1331-1337

[16] Rathore SS, Curtis JP, Wang Y, Bristow MR, Krumholz HM. Association of serum digoxin concentration and outcomes in patients with heart failure. JAMA 2003; 289: 871-878 
[17] Georgiopoulou VV, Kalogeropoulos AP, Giamouzis G, Agha SA, Rashad MA, Waheed S, Laskar S, Smith AL, Butler J. Digoxin therapy does not improve outcomes in patients with advanced heart failure on contemporary medical therapy. Circ Heart Fail 2009; 2: 90-97

[18] Freeman JV, Yang J, Sung SH, Hlatky MA, Go AS. Effectiveness and safety of digoxin among contemporary adults with incident systolic heart failure. Circ Cardiovasc Qual Outcomes 2013; 6: 525-533

[19] Opie LH. Digitalis, yesterday and today, but not forever. Circ Cardiovasc Qual Outcomes 2013; 6: 511-513

[20] Vamos M, Erath JW, Hohnloser SH. Digoxin-associated mortality: a systematic review and meta-analysis of the literature. Eur Heart J 2015; 36: $1831-1838$

[21] Chaggar PS, Shaw SM, Williams SG. Is foxglove effective in heart failure? Cardiovasc Ther 2015; 33: 236-241

[22] Ziff O], Lane DA, Samra M, Griffith M, Kirchhof P, Lip GY, Steeds RP, Townend J, Kotecha D. Safety and efficacy of digoxin: systematic review and meta-analysis of observational and controlled trial data. BMJ 2015; 351: h4451

[23] Shiratori O. Growth inhibitory effect of cardiac glycosides and aglycones on neoplastic cells: in vitro and in vivo studies. Gan 1967; 58: 521-528

[24] Stenkvist B, Bengtsson E, Eriksson O, Holmquist J, Nordin B, WestmanNaeser S. Cardiac glycosides and breast cancer. Lancet 1979; 1: 563

[25] Slingerland M, Cerella C, Guchelaar H], Diederich M, Gelderblom H. Cardiac glycosides in cancer therapy: from preclinical investigations towards clinical trials. Invest New Drugs 2013; 31: 1087-1094

[26] Alevizopoulos K, Calogeropoulou T, Lang F, Stournaras C. Na ${ }^{+} / \mathrm{K}^{+}$ATPase inhibitors in cancer. Curr Drug Targets 2014; 15: 988-1000

[27] Calderón-Montaño JM, Burgos-Morón E, Orta ML, Maldonado-Navas D, García-Domínguez I, López-Lázaro M. Evaluating the cancer therapeutic potential of cardiac glycosides. Biomed Res Int 2014; 2014: 794930

[28] Durlacher CT, Chow K, Chen XW, He ZX, Zhang X, Yang T, Zhou SF. Targeting $\mathrm{Na}(+) / \mathrm{K}(+)$-translocating adenosine triphosphatase in cancer treatment. Clin Exp Pharmacol Physiol 2015; 42: 427-443

[29] Patel S. Plant-derived cardiac glycosides: Role in heart ailments and cancer management. Biomed Pharmacother 2016; 84: 1036-1041

[30] Diederich M, Muller F, Cerella C. Cardiac glycosides: From molecular targets to immunogenic cell death. Biochem Pharmacol 2017; 125: 1-11

[31] Lancaster MC, Vegad JL. Suppression of the early inflammatory response in the sheep by strophanthin G. Nature 1967; 213: 840-841

[32] De Vasconcelos DI, Leite JA, Carneiro LT, Piuvezam MR, de Lima MR, de Morais LC, Rumjanek VM, Rodrigues-Mascarenhas S. Anti-inflammatory and antinociceptive activity of ouabain in mice. Mediators Inflamm 2011; 2011: 912925

[33] Leite JA, Alves AK, Galvão JG, Teixeira MP, Cavalcante-Silva LH, Scavone C, Morrot A, Rumjanek VM, Rodrigues-Mascarenhas S. Ouabain modulates zymosan-induced peritonitis in mice. Mediators Inflamm 2015; 2015: 265798

[34] Esposito AL. Digoxin disrupts the inflammatory response in experimental pneumococcal pneumonia. J Infect Dis 1985; 152: 14-23

[35] Jacob PL, Leite JA, Alves AK, Rodrigues YK, Amorim FM, Neris PL, Oliveira MR, Rodrigues-Mascarenhas S. Immunomodulatory activity of ouabain in Leishmania leishmania amazonensis-infected Swiss mice. Parasitol Res 2013; 112: 1313-1321

[36] Huh JR, Leung MW, Huang P, Ryan DA, Krout MR, Malapaka RR, Chow J, Manel N, Ciofani M, Kim SV, Cuesta A, Santori FR, Lafaille JJ, Xu HE, Gin DY, Rastinejad F, Littman DR. Digoxin and its derivatives suppress TH17 cell differentiation by antagonizing RORgammat activity. Nature 2011; 472: 486-490

[37] Lee J, Baek S, Lee J, Lee J, Lee DG, Park MK, Cho ML, Park SH, Kwok SK. Digoxin ameliorates autoimmune arthritis via suppression of Th17 differentiation. Int Immunopharmacol 2015; 26: 103-111
[38] Hinshaw S], Ogbeifun O, Wandu WS, Lyu C, Shi G, Li Y, Qian H, Gery I. Digoxin inhibits induction of experimental autoimmune uveitis in mice, but causes severe retinal degeneration. Invest Ophthalmol Vis Sci 2016; 57: 1441-1447

[39] Forshammar J, Block L, Lundborg C, Biber B, Hansson E. Naloxone and ouabain in ultralow concentrations restore $\mathrm{Na}^{+} / \mathrm{K}^{+}$-ATPase and cytoskeleton in lipopolysaccharide-treated astrocytes. J Biol Chem 2011; 286: 31586-31597

[40] Forshammar ], Jörneberg P, Björklund U, Westerlund A, Lundborg C, Biber B, Hansson E. Anti-inflammatory substances can influence some glial cell types but not others. Brain Res 2013; 1539: 34-40

[41] Kinoshita PF, Yshii LM, Vasconcelos AR, Orellana AM, Lima Lde S, Dave AP, Rossoni LV, Kawamoto EM, Scavone C. Signaling function of Na,KATPase induced by ouabain against LPS as an inflammation model in hippocampus. J Neuroinflammation 2014; 11: 218

[42] Srivastava M, Eidelman O, Zhang J, Paweletz C, Caohuy H, Yang Q, Jacobson KA, Heldman E, Huang W, Jozwik C, Pollard BS, Pollard HB. Digitoxin mimics gene therapy with CFTR and suppresses hypersecretion of IL-8 from cystic fibrosis lung epithelial cells. Proc Natl Acad Sci U S A 2004; 101: 7693-7698

[43] Yang Q, Huang W, Jozwik C, Lin Y, Glasman M, Caohuy H, Srivastava M, Esposito D, Gillette W, Hartley J, Pollard HB. Cardiac glycosides inhibit TNF-alpha/NF-kappaB signaling by blocking recruitment of TNF receptor-associated death domain to the TNF receptor. Proc Natl Acad Sci U S A 2005; 102: 9631-9636

[44] Zeitlin PL, Diener-West M, Callahan KA, Lee S, Talbot CC jr., Pollard B, Boyle MP, Lechtzin N. Digitoxin for airway inflammation in cystic fibrosis: preliminary assessment of safety, pharmacokinetics, and dose finding. Ann Am Thorac Soc 2017; 14: 220-229

[45] Quastel MR, Kaplan JG. Inhibition by ouabain of human lymphocyte transformation induced by phytohaemagglutinin in vitro. Nature 1968; 219: $198-200$

[46] Quastel MR, Kaplan JG. Lymphocyte stimulation: the effect of ouabain on nucleic acid and protein synthesis. Exp Cell Res 1970; 62: 407-420

[47] Takada Y, Matsuo K, Ogura H, Bai L, Toki A, Wang L, Ando M, Kataoka T. Odoroside $\mathrm{A}$ and ouabain inhibit $\mathrm{Na}^{+} / \mathrm{K}^{+}-\mathrm{ATPase}$ and prevent NF-kappaBinducible protein expression by blocking $\mathrm{Na}^{+}$-dependent amino acid transport. Biochem Pharmacol 2009; 78: 1157-1166

[48] Szamel M, Somogyi ], Csukás I, Solymosy F. Effect of ouabain on macromolecular synthesis during the cell cycle in mitogen-stimulated human lymphocytes. Biochim Biophys Acta 1980; 633: 347-360

[49] Szamel M, Resch K. Inhibition of lymphocyte activation by ouabain. Interference with the early activation of membrane phospholipid metabolism. Biochim Biophys Acta 1981; 647: 297-301

[50] Pires V, Harab RC, Olej B, Rumjanek VM. Ouabain effects on activated lymphocytes: augmentation of CD25 expression on TPA-stimulated cells and of CD69 on PHA-and TPA-stimulated cells. Int J Immunopharmacol 1997; 19: $143-148$

[51] Stoeck M, Northoff H, Resch K. Inhibition of mitogen-induced lymphocyte proliferation by ouabain: interference with interleukin 2 production and interleukin 2 action. J Immunol 1983; 131: 1433-1437

[52] Lillehoj $H$, Shevach EM. A comparison of the effects of cyclosporin A, dexamethasone, and ouabain on the interleukin-2 cascade. J Immunopharmacol 1985; 7: 267-284

[53] Dornand J, Favero J, Bonnafous JC, Mani JC. Mechanism whereby ouabain inhibits human T lymphocyte activation: effect on the interleukin 2 pathway. Immunobiology 1986; 171: 436-450

[54] Falciola J, Volet B, Anner RM, Moosmayer M, Lacotte D, Anner BM. Role of cell membrane Na,K-ATPase for survival of human lymphocytes in vitro. Biosci Rep 1994; 14: 189-204

[55] Szamel M, Schneider S, Resch K. Functional interrelationship between $\left(\mathrm{Na}^{+}+\mathrm{K}^{+}\right)$-ATPase and lysolecithin acyltransferase in plasma membranes 
of mitogen-stimulated rabbit thymocytes. J Biol Chem 1981; 256: 9198 9204

[56] Rodrigues-Mascarenhas S, Bloise FF, Moscat ], Rumjanek VM. Ouabain inhibits p38 activation in thymocytes. Cell Biol Int 2008; 32: 1323-1328

[57] Rodrigues-Mascarenhas S, Echevarria-Lima J, Fernandes dos Santos N, Rumjanek VM. CD69 expression induced by thapsigargin, phorbol ester and ouabain on thymocytes is dependent on external $\mathrm{Ca}^{2+}$ entry. Life Sci 2003; 73: 1037-1051

[58] Mann CL, Bortner CD, Jewell CM, Cidlowski JA. Glucocorticoid-induced plasma membrane depolarization during thymocyte apoptosis: association with cell shrinkage and degradation of the $\mathrm{Na}(+) / \mathrm{K}(+)$-adenosine triphosphatase. Endocrinology 2001; 142: 5059-5068

[59] Rodrigues-Mascarenhas S, dos Santos NF, Rumjanek VM. Synergistic effect between ouabain and glucocorticoids for the induction of thymic atrophy. Biosci Rep 2006; 26: 159-169

[60] Milthorp P, Quastel MR, Kaplan JG, Vogelfanger I]. Effect of the inhibition of cation transport by ouabain on plaque formation by splenic lymphoid cells: time course and dose response. Cell Immunol 1974; 14: 128-133

[61] Maubach K, Foey AD, Hall ND. Impaired activity of thiol-dependent ATPases in rheumatoid mononuclear cell membranes. Agents Actions 1993; 39 (Spec No): C107-C109

[62] Foey AD, Crawford A, Hall ND. Modulation of cytokine production by human mononuclear cells following impairment of $\mathrm{Na}$, K-ATPase activity. Biochim Biophys Acta 1997; 1355: 43-49

[63] Matsumori A, Ono K, Nishio R, Igata H, Shioi T, Matsui S, Furukawa Y, Iwasaki A, Nose Y, Sasayama S. Modulation of cytokine production and protection against lethal endotoxemia by the cardiac glycoside ouabain. Circulation 1997; 96: 1501-1506

[64] Matsumori A, Ono K, Nishio R, Nose Y, Sasayama S. Amlodipine inhibits the production of cytokines induced by ouabain. Cytokine 2000; 12 : 294-297
[65] Ihenetu K, Espinosa R, de Leon R, Planas G, Perez-Pinero A, Waldbeser L. Digoxin and digoxin-like immunoreactive factors (DLIF) modulate the release of pro-inflammatory cytokines. Inflamm Res 2008; 57: 519-523

[66] Sowa G, Przewłocki R. Ouabain enhances the lipopolysaccharide-induced nitric oxide production by rat peritoneal macrophages. Immunopharmacology 1997; 36: 95-100

[67] Valente RC, Nascimento CR, Araujo EG, Rumjanek VM. mCD14 expression in human monocytes is downregulated by ouabain via transactivation of epithelial growth factor receptor and activation of p38 mitogenactivated protein kinase. Neuroimmunomodulation 2009; 16: 228-236

[68] Teixeira MP, Rumjanek VM. Ouabain affects the expression of activation markers, cytokine production, and endocytosis of human monocytes. Mediators Inflamm 2014; 2014: 760368

[69] Ward PA, Becker EL. Potassium reversible inhibition of leukotaxis by ouabain. Life Sci 1970; 9: 355-360

[70] De Moraes VL, Olej B, de la Rocque L, Rumjanek VM. Lack of sensitivity to ouabain in natural killer activity. FASEB 」 1989; 3: 2425-2429

[71] Nascimento CR, Valente RC, Echevarria-Lima J, Fontes CF, de AraujoMartins L, Araujo EG, Rumjanek VM. The influence of ouabain on human dendritic cells maturation. Mediators Inflamm 2014; 2014: 494956

[72] Bereta ], Cohen MC, Bereta M. Stimulatory effect of ouabain on VCAM-1 and iNOS expression in murine endothelial cells: involvement of NF-kappa B. FEBS Lett 1995; 377: 21-25

[73] Jagielska J, Salguero G, Schieffer B, Bavendiek U. Digitoxin elicits anti-inflammatory and vasoprotective properties in endothelial cells: Therapeutic implications for the treatment of atherosclerosis? Atherosclerosis 2009; 206: 390-396

[74] Goto A, Yamada K, Nagoshi H, Terano Y, Omata M. Stress-induced elevation of ouabainlike compound in rat plasma and adrenal. Hypertension 1995; 26: 1173-1176

[75] Gottlieb SS, Rogowski AC, Weinberg M, Krichten CM, Hamilton BP, Hamlyn JM. Elevated concentrations of endogenous ouabain in patients with congestive heart failure. Circulation 1992; 86: 420-425 